ISBN 978-93-84468-94-1

International Conference on Education, Business and Management (ICEBM-2017)

Bali (Indonesia) Jan. 8-9, 2017

\title{
Factors Affecting Elderly Consumer Behavior on Choosing Cellular Phone,Bangkok
}

\author{
Dr. Watchara Yeesuntes, Mr. Sompord Yamchan \\ Post graduate school of Business Administration Kasembundit University, Bangkok
}

\begin{abstract}
The primary purpose of this study was to determine factors affecting elderly consumer behavior and marketing mix on choosing cellular phone. Samples were 400 elderly consumer whose age over 45 years old living in Bangkok by using a check list and rating scale questionnaire. The statistics used for data analysis were percentage, mean, standard deviation, Chi-Square, and regression analysis.

On the basis of the results of this research, it could be concluded that most of respondents were males, age between 56-60 years old, high or vocational school graduated, average monthly income between 9,000-15,000 baht, most of elderly consumer behavior of choosing cellular phone were Iphone, sale representative influenced in helping to select the brand, average phone cost between 15,000-20,000 baht, and reason to selected cellular phone was a beauty of it, distribution channel was any cellular phone shop, and period of cellular phone usage about 2 years. Factors of marketing mix affecting elderly consumer behavior in choosing cellular phone were in high level consisting of marketing promotion, free accessories with cellular phone purchased, sale representative to suggest products, and cellular phone advertising through multimedia, post purchased warrantee, resolution of camera, users friendly, stylist, well-known and reputable brand name, purchased with installment plan, reasonable pricing to quality of cellular phone, widespread prices range with discount prices, distribution channel within department stores and through internet by e-commerce, and display models at distribution channel. Hypothesis testing revealed that the different of personal factors, such as gender, age, level of education, and average monthly income effected elderly consumer behavior on choosing cellular phone. Factors of marketing mix correlated to elderly consumer behavior on choosing cellular phone, such as products and prices with statistical significant 0.05 level.

Recommendations from the study were that entrepreneur should offer cellular phones with technology leading, beauty, appropriate prices with quality, wide range and comparable prices, distribution channel nationwide, marketing promotion, discount prices when introduce new phones, free gift with purchased, and advertising though multimedia in order to get consumer attention.
\end{abstract}

Keywords: factor, behavior, and marketing.

\section{Introduction}

Today, people realized that Thailand has become an aging society already. But what many people, especially those involved with the planning and policy might not expect is that the population of Thailand is aging rapidly, so Thailand has become a "social of age" since 2548, when the proportion of elderly people (60 years and above) go up to 10 percent of the total population. Thailand is about to become a "social aging completely" when the population aged 60 years and above up to 20 percent in 2564, or in just seven years from now and is expected to be highly social of age the next 20 years, when the population aged 60 and over accounted for 28 percent of the total population.

The speed of the aging of the population of Thailand as a result of the population was born and later died at the end of World War II. The "million population born" (born 2506-2526) are moving into old age 
population in 2557. The million population born were between 31-51 years old and were much higher. The elderly will become a fully capacity on the next ten years ahead.

From introduction mentioned above, researcher are interested in studying factors affecting elderly consumer behavior and marketing mix on choosing cellular phone in order to service to elderly and meet their demand.

\section{Concept, Theories of the Marketing Mix}

The 4Ps of marketing is a model for enhancing the components of your 'marketing mix' - the way in which you take a new product or service to market. It helps you to define your marketing options in terms of price, product, promotion, and place so that your offering meets a specific customer need or demand.

You just need to create a product that a particular group of people want, put it on sale some place that those same people visit regularly, and price it at a level which matches the value they feel they get out of it; and do all that at a time they want to buy. Then you've got it made!

There's a lot of truth in this idea. However, a lot of hard work needs to go into finding out what customers want, and identifying where they do their shopping. Then you need to figure out how to produce the item at a price that represents value to them, and get it all to come together at the critical time.

But if you get just one element wrong, it can spell disaster. You could be left promoting a car with amazing fuel-economy in a country where fuel is very cheap; or publishing a textbook after the start of the new school year, or selling an item at a price that's too high - or too low - to attract the people you're targeting.

The marketing mix is a good place to start when you are thinking through your plans for a product or service, and it helps you avoid these kinds of mistakes.

"Marketing mix" is a general phrase used to describe the different kinds of choices organizations have to make in the whole process of bringing a product or service to market. The 4Ps is one way - probably the best-known way - of defining the marketing mix, and was first expressed in 1960 by E J McCarthy ${ }^{1}$. The 4Ps are: Product (or Service), Place, Price, and Promotion.

\section{Purpose of the Study}

The purpose of this study was to determine factors affecting elderly consumer behavior and marketing mix on choosing cellular phone.

\section{Conceptual frameworks of the study}

The marketing factors that affecting elderly consumer behavior and marketing mix on choosing cellular phone.

${ }^{1}$ McCarthy, Jerome E. (1960). Basic Marketing. A Managerial Approach. Homewood, IL: Richard D. Irwin. 
Independent Variables
Dependent Variables

\section{Factors of Personal \\ 1. Gender \\ 2. Age \\ 3. Level of education \\ 4. Average monthly income}

Marketing mic factors

1. Products

2. Prices

3. Distribution channel

4. Marketing promotion

\section{Research Methodology}

\subsection{Sample Selection}

Samples were 400 elderly consumer whose age over 45 years old living in Bangkok

\subsection{Data collection procedure}

The questionnaires were distributed to sample of 400 elderly consumer whose age over 45 years old living in Bangkok. A total of 400 usable questionnaires were returned back to the researcher, yielding a 100 percent response rate and no missing data.

Results analysis of the average picture of opinions regarded factors affecting elderly consumer behavior and marketing mix on choosing cellular phone consisting of follow aspects.

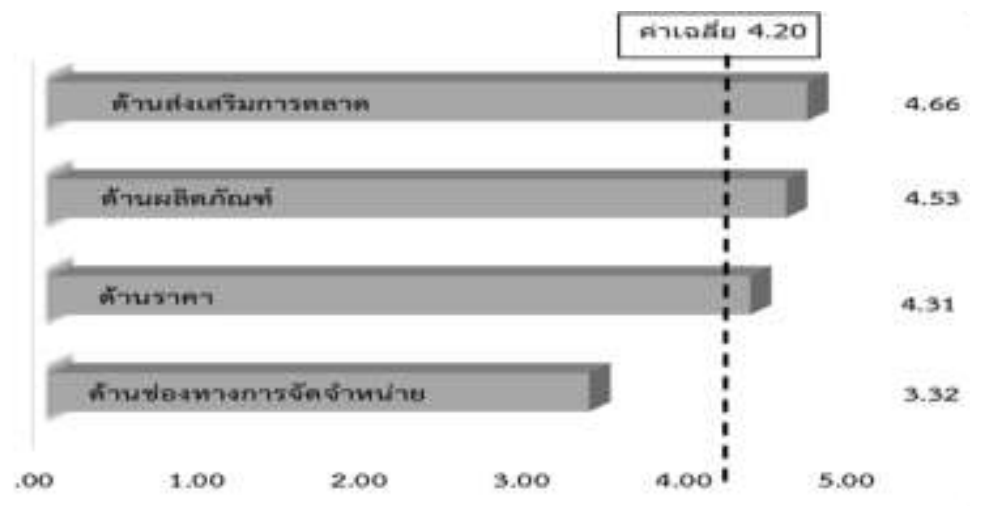


From analysis study revealed that the average picture of opinions regarding factors affecting elderly consumer behavior and marketing mix on choosing cellular phone were in high level $(\bar{x}=4.20)$ consisting of following aspects: Marketing promotion $(\bar{x}=4.66)$ and products $(\bar{x}=4.53)$ were in highest level of the opinions. As for prices aspect $(\bar{x}=4.31)$ were in high level of the opinions. Finally, for distribution channel $(\bar{x}=3.31)$ were in medium level of the opinion.

TABLE I: comparison of different personal factors of elderly consumer such as gender effecting elderly consumer behavior on choosing cellular phone.

\begin{tabular}{|c|c|c|}
\hline \multicolumn{3}{|l|}{ Gender } \\
\hline Elderly Consumer behavior on choosing cellular phone & Chi Square & Sig. \\
\hline Cellular phone brand name & 250.792 & $0.006^{*}$ \\
\hline Who influence in decision & 71.518 & $0.004 *$ \\
\hline Prices of cellular phones & 23.106 & $0 . * 001$ \\
\hline Reason influencing decision on choosing cellular phone & 18.524 & $0.001 *$ \\
\hline Distribution channel & 26.915 & $0 . * 007$ \\
\hline Period of cellular phone usage & 13.039 & $0.005^{*}$ \\
\hline
\end{tabular}

*Statistical significant $<0.05$

As shows on table 1: hypothesis testing revealed that the different of personal factor, such as gender affected the elderly consumer behavior on choosing cellular phone, the probability value of factors consisted of prices, reason to buy cellular phone, period of phone usaged, cellular brand name, and distribution channel (p) equal 0.0010 .0010 .0040 .0050 .0060 .007 test values less than 0.05 which rejected main hypothesis (H0), accepted secondary hypothesis (H1) mean factors of personal different such as gender affected the elderly consumer behavior on choosing cellular phone at Significant 0.05 level.

TABLE II: comparison of different personal factors of elderly consumer such as age effecting elderly consumer behavior on choosing cellular phone.

\begin{tabular}{|l|c|c|}
\hline \multicolumn{2}{|c|}{ Age } & Sig. \\
\hline \multicolumn{1}{|c|}{ Elderly Consumer behavior on choosing cellular phone } & Chi Square & 271.915 \\
\hline Cellular phone brand name & 283.684 & $0.000^{*}$ \\
\hline Who influence in decision & 45.173 & $0.000^{*}$ \\
\hline Prices of cellular phones & 53.150 & $0.000^{*}$ \\
\hline Reason influencing decision on choosing cellular phone & 26.395 & $0.049^{*}$ \\
\hline Distribution channel & 40.128 & $0.000^{*}$ \\
\hline Period of cellular phone usage
\end{tabular}

*Statistical significant $<\mathbf{0 . 0 5}$

As shows on table 2: hypothesis testing revealed that the different of personal factor, such as age affected the elderly consumer behavior on choosing cellular phone, the probability value of factors consisted of prices, reason to buy cellular phone, period of phone usage, cellular brand name, and distribution channel (p) equal 0.0000 .0000 .0000 .0000 .0000 .049 test values less than 0.05 which rejected the main hypothesis $(\mathrm{H} 0)$, accepted secondary hypothesis $(\mathrm{H} 1)$ mean factors of personal different such as age affected the elderly consumer behavior on choosing cellular phone at Significant 0.05 level. 
TABLE III: comparison of different personal factors of elderly consumer such as level of education effecting elderly consumer behavior on choosing cellular phone.

\begin{tabular}{|c|c|c|}
\hline \multicolumn{3}{|l|}{ Level of education } \\
\hline Elderly Consumer behavior on choosing cellular phone & Chi Square & Sig. \\
\hline Cellular phone brand name & 233.513 & $0.000 *$ \\
\hline Who influence in decision & 110.871 & $0.000 *$ \\
\hline Prices of cellular phones & 33.082 & $0.001 *$ \\
\hline Reason influencing decision on choosing cellular phone & 425.148 & $0.000 *$ \\
\hline Distribution channel & 462.435 & $0.000^{*}$ \\
\hline Period of cellular phone usage & 30.741 & $0.000 *$ \\
\hline
\end{tabular}

*Statistical significant $<0.05$

As shows on table 3: hypothesis testing revealed that the different of personal factor, such as Level of education affected the elderly consumer behavior on choosing cellular phone, the probability value of factors consisted of prices, reason to buy cellular phone, period of phone usage, cellular brand name, and distribution channel (p) equal 0.0000 .0000 .0010 .0000 .0000 .049 test values less than 0.05 which rejected the main hypothesis $(\mathrm{H} 0)$, accepted secondary hypothesis $(\mathrm{H} 1)$ mean factors of personal different such as Level of education affected the elderly consumer behavior on choosing cellular phone at Significant 0.05 level.

TABLE IV: comparison of different personal factors of elderly consumer such as average monthly income effecting elderly consumer behavior on choosing cellular phone.

\begin{tabular}{|c|c|c|}
\hline \multicolumn{3}{|l|}{ Average monthly income } \\
\hline Elderly Consumer behavior on choosing cellular phone & Chi Square & Sig. \\
\hline Cellular phone brand name & 246.692 & $0.000 *$ \\
\hline Who influence in decision & 51.055 & $0.000 *$ \\
\hline Prices of cellular phones & 433.256 & $0.000 *$ \\
\hline Reason influencing decision on choosing cellular phone & 108.135 & $0.000 *$ \\
\hline Distribution channel & 47.743 & $0.000 *$ \\
\hline Period of cellular phone usage & 31.558 & $0.002 *$ \\
\hline
\end{tabular}

*Statistical significant $<0.05$

As shows on table 4: hypothesis testing revealed that the different of personal factor, such as Average monthly income affected the elderly consumer behavior on choosing cellular phone, the probability value of factors consisted of prices, reason to buy cellular phone, period of phone usage, cellular brand name, and distribution channel (p) equal 0.0000 .0000 .0000 .0000 .0000 .000 test values less than 0.05 which rejected the main hypothesis (H0), accepted secondary hypothesis (H1) mean factors of personal different such as Average monthly income affected the elderly consumer behavior on choosing cellular phone at Significant 0.05 level. 
TABLE V: shows results from hypothesis testing by Regression and the important of factors affecting elderly consumer behavior and marketing mix on choosing cellular phone.

\begin{tabular}{|c|c|c|c|c|c|c|}
\hline \multirow[t]{2}{*}{ Model } & \multicolumn{2}{|c|}{$\begin{array}{l}\text { Unstandardized } \\
\text { coefficients }\end{array}$} & \multirow{2}{*}{$\begin{array}{c}\text { Standardized } \\
\text { coefficients } \\
\text { Beta } \\
\end{array}$} & \multirow[t]{2}{*}{$\mathrm{t}$} & \multirow[t]{2}{*}{ Sig. } & \multirow{3}{*}{ Testing } \\
\hline & $\mathrm{B}$ & Std. error & & & & \\
\hline (Constant) & 1.936 & .330 & & 5.864 & .000 & \\
\hline \multicolumn{7}{|c|}{ Products aspect } \\
\hline Famous brand name & .588 & .038 & .625 & 15.476 & $.000^{*}$ & correlated \\
\hline Stylist & .147 & .032 & .185 & 4.590 & $.000^{*}$ & correlated \\
\hline Warrantee & .090 & .055 & .122 & 1.639 & .102 & $\begin{array}{l}\text { No } \\
\text { relationship }\end{array}$ \\
\hline \multicolumn{7}{|c|}{ Prices } \\
\hline Wide range of prices & 130 & .062 & .129 & 2.082 & .078 & $\begin{array}{l}\text { No } \\
\text { relationship }\end{array}$ \\
\hline Appropriate prices \& quality & .053 & .021 & .104 & 2.565 & $.011^{*}$ & correlated \\
\hline Installment plan & .027 & .034 & .027 & .786 & .432 & $\begin{array}{l}\text { No } \\
\text { relationship }\end{array}$ \\
\hline \multicolumn{7}{|c|}{ Distribution channel } \\
\hline Offer at shopping center & .007 & .030 & .007 & .233 & .816 & $\begin{array}{l}\text { No } \\
\text { relationship }\end{array}$ \\
\hline Products sample at the shop & .012 & .031 & .013 & .388 & .699 & $\begin{array}{l}\text { No } \\
\text { relationship }\end{array}$ \\
\hline \multicolumn{7}{|c|}{ Marketing promotion } \\
\hline Advertising thru multimedia & .035 & .030 & .038 & 1.197 & .232 & $\begin{array}{l}\text { No } \\
\text { relationship }\end{array}$ \\
\hline Free gift with purchased & .042 & .044 & .038 & .955 & .340 & $\begin{array}{l}\text { No } \\
\text { relationship }\end{array}$ \\
\hline
\end{tabular}

*Statistical significant $<0.05$

From table 5: shows results from hypothesis testing by Regression and the important of factors affecting elderly consumer behavior and marketing mix on choosing cellular phone revealed that products with well-known brand name (Sig.= 0.000), modern styles (Sig.=0.032), and prices aspect with appropriate with quality $(\mathrm{Sig} .=0.011)$ correlated to elderly consumer behavior on choosing cellular phone.

\section{Summary of Study Results}

Findings from study indicated that most of respondents were males, age between 56-60 years old, high or vocational school graduated, average monthly income between 9,000-15,000 baht.

Most of 400 elderly consumer preferred Iphone, sale representative influenced in helping to select the brand, average phone cost between 15,000-20,000 baht, and reason to selected cellular phone was a beauty of it, distribution channel was at cellular phone shop, and period of cellular phone usage about 2 years.

Summary of aspects of factors affecting elderly consumer behavior and marketing mix on choosing cellular phone.

The average picture of opinions on marketing mix revealed that factors affecting elderly consumer behavior and marketing mix on choosing cellular phone were in high level consisted of marketing promotion, products, prices, and distribution channel, respectively.

Products aspect: revealed from study found that the picture of opinions were in highest level, such as warrantee, camera resolution, users friendly, modern styles, reputable brand name, respectively.

Prices aspect: revealed from study found that the picture of opinions were in high level, such as installment plan, appropriate prices and quality, wide range of prices, and offer discount prices, respectively. 
Distribution channel aspect: revealed from study found that the picture of opinions were in medium level, such as offer products in shopping center, e-commerce, sample of products at the stores, respectively.

Marketing promotion aspect: revealed from study found that the picture of opinions were in highest level, such as free accessory with purchased, sale representative, and advertising though multimedia, respectively.

\section{Suggestions for future research}

This study selected samplings group from 400 elderly consumer whose age over 45 years old living in Bangkok only. Therefore, the future study should select samplings group from different demographic area and bring data to compare and get the results to set a new guideline for benefit of all consumers and organizations.

\section{References}

[1] Juthapach Vanichakij. (2555). Comparing value of cellular phone between Apple Iphone and Samsung Galaxy affecting attitude of cellular phone users in Bangkok and perimeter, Thesis, Master of Business Administration, Kasetsart University.

[2] Chamaiporn Pardsri. (2555). Marketing factors influencing consumer decision on buying cellular Phone in Kannayao district, Thesis, Master of Business Administration, Silpakorn University.

[3] McCarthy, Jerome E. (1960). Basic Marketing. A Managerial Approach. Homewood, IL: Richard D. Irwin.

[4] Thongchai Santivong. (2549). Consumer market behavior, $11^{\text {th }}$ edition, Prachumchang publisher, Bangkok.

[5] Taratip Walsri. (2555). Correlation between marketing factor and consumer behavior on buying Cellular phone in Bangkok, Thesis, Master of Business Administration, Technology Ratchamonkol. Thunyaburi district Siriwan Saerirat. (2541). Marketing Strategy, Marketing management and case study, Thera film and Chaitech publisher, Bangkok.

[6] Siriwan Saerirat \& Associate. (2543). Principle of Marketing, Thera film and Chaitech publisher, Bangkok.

[7] Siriwan Saerirat \& Associate. (2546). New era of marketing management, Thamasarn publisher, Bangkok.

[8] Siriprapa Vuthichon. (2555). Personal factors affecting consumer purchasing cellular phone, in Thailand, Thesis, Master of Business Administration, Ratchaphat University, Ubonratchathani.

[9] Saeri Vongmonta. (2542). Consumer behavior analysis, Thera film and Chaitech publisher, Bangkok.

[10] Surasit Intah. (2551). Study correlation between marketing communication and traveler behavior. In Mae Sariang district, Maehongsorn Province. Thesis, Master of Business Administration, Burapha University. 